\title{
Homogeneous ice formation in convective cloud outflow regions
}

\author{
B. Kärcher (1) \\ German Aerospace Agency (DLR), Institute for Atmospheric Physics (IPA), Wessling, Germany \\ ${ }^{\star}$ Correspondence to: B. Kärcher, DLR Oberpfaffenhofen, Institut für Physik der Atmosphäre, 82234 Wessling, Germany. \\ E-mail: bernd.kaercher@dlr.de
}

\begin{abstract}
Homogeneous droplet freezing in the warm cirrus regime $(230-240 \mathrm{~K})$ is investigated along idealized convective cloud trajectories using a spectral parcel model developed to track droplet freezing events accurately. The novel model is described and used to study ice formation from rapidly ascending (vertical velocity $0.6-6 \mathrm{~m} \mathrm{~s}^{-1}$ ) air parcels containing cloud condensation nuclei (CCN) and liquid water droplets. Homogeneous freezing events in warm cirrus are affected by latent heat exchange and produce a mode of small ice crystals with maximum dimensions $10-100 \mu \mathrm{m}$ after initial supersaturation quenching. During the formation stage, ice-crystal number concentrations formed homogeneously in convective cloud outflow are hardly affected by ice-crystal settling and depend sensitively on vertical velocity. In the case of CCN activation into cloud water droplets prior to or along with freezing, relative humidity variations also result in widely varying ice numbers that are insensitive to CCN solubility. These results offer pointers on how further progress can be achieved in simulating and better understanding the formation of upper tropospheric ice clouds originating from convective detrainment zones.
\end{abstract}

Key Words: supercooled cloud droplets; homogeneous freezing; cloud microphysics; numerical simulation; spectral parcel model

Received 12 January 2017; Revised 1 May 2017; Accepted 4 May 2017; Published online in Wiley Online Library 21 June 2017

\section{Introduction}

Homogeneous freezing of supercooled, liquid water containing particles is the most fundamental microphysical process leading to cloud ice formation, requiring only the presence of ubiquitous cloud condensation nuclei $(\mathrm{CCN})$ and a dynamical forcing - usually cooling - to initiate water phase transitions. Evidence for homogeneous freezing of cloud droplets occurring at the tops of convective clouds is available from in situ measurements (Rosenfeld and Woodley, 2003; Stith et al., 2014). To assess the role of heterogeneous ice nuclei (IN) in atmospheric ice formation processes reliably, a sound understanding of homogeneous droplet freezing is essential.

An analytical approach has been presented describing homogeneous ice formation from water droplets in liquid clouds (Kärcher and Seifert, 2016, hereinafter referred to as KS16) or from supercooled aerosol particles in cirrus (pure ice clouds that lack a liquid cloud droplet phase: Kärcher and Lohmann, 2002). This approach rests on the concept of freezing-relaxation, which examines the supersaturation history in moist adiabatic air parcels by showing that the number of nucleated ice crystals is largely determined by the condition that the rate of ice supersaturation quenching due to water-vapour deposition on the newly formed ice crystals equals the rate of ice supersaturation increase due to dynamical forcing induced by a prescribed updraught speed.

According to these and a number of follow-on studies, primary ice formation is strongly controlled by the dynamical forcing and the impact of IN on homogeneous freezing events diminishes in conditions of sufficiently strong forcing. In such conditions, IN reduce homogeneously nucleated ice-crystal number concentrations significantly or prevent homogeneous freezing from occurring only if they are sufficiently abundant.

The present work continues this research by means of detailed numerical simulations of droplet and ice microphysics at temperatures $230-240 \mathrm{~K}$, in a first step without consideration of IN effects. In this temperature (warm cirrus) regime, wherein homogeneous freezing of supercooled aerosol particles takes place only with exceedingly low probability, efficient homogeneous freezing of liquid water droplets takes place. Those droplets are either transported from within cloud to high-altitude outflow regions or form from $\mathrm{CCN}$ available within those regions. We examine a deep convection case study of homogeneous droplet freezing, in which important variables are constrained by in situ observations. Our previous work on this issue (KS16) is taken one step further by adding effects of convectively driven CCN activation in the simulations to explore the liquid-phase control of this ice formation pathway.

To this end, we have developed a numerical parcel model that is tailored towards an accurate treatment of ice nucleation and depositional growth from a prescribed population of CCN (that might be internally mixed with heterogeneous immersion freezing nuclei) and the supercooled cloud droplets evolving from them. Effects of CCN and IN on ice formation in mixed-phase clouds have in the past been studied using a parcel model framework ( $\mathrm{Li}$ et al., 2013, and references therein) employing classical nucleation theory to model cloud-droplet freezing, with an emphasis on 


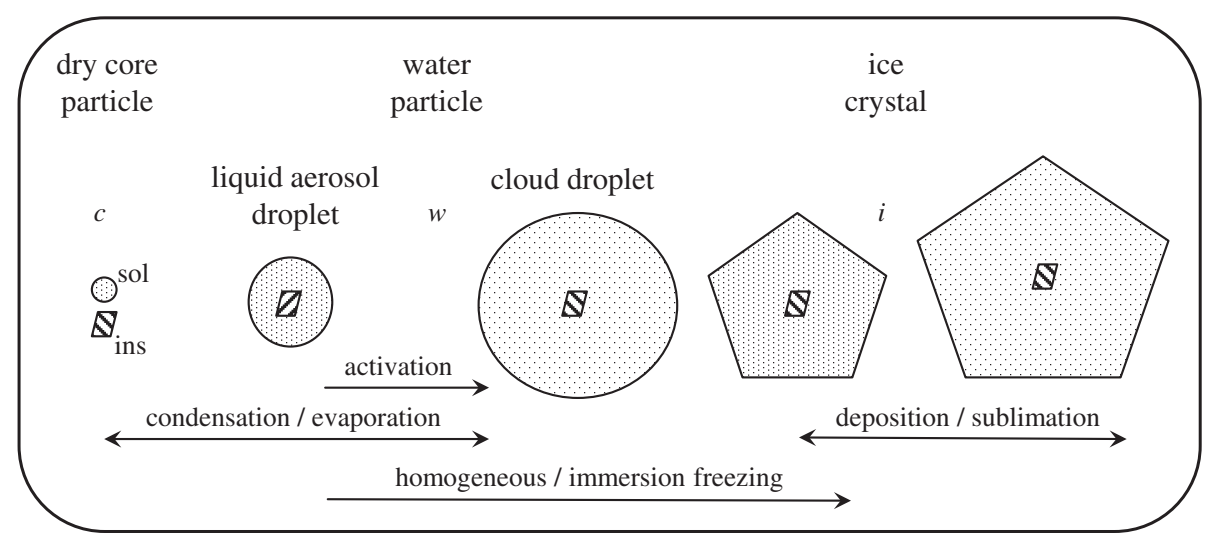

Figure 1. Schematic of particle types and microphysical transformation pathways realized in the spectral parcel model primeICE. CCN are supercooled aqueous aerosol particles containing hygroscopic solutes (sol) and optionally insoluble immersion ice nuclei (ins) as dry cores (c). The solute material dissolves in the presence of condensed water, creating solution droplets. Those sub- $\mu \mathrm{m}$ sized aqueous droplets equilibrate by condensation or evaporation of small amounts of water vapour in a liquid water subsaturated environment and may activate into $\mu \mathrm{m}$-sized cloud droplets by condensing large amounts of supersaturated vapour. Together, liquid aerosol and cloud droplets are denoted as water particles $(w)$. They may nucleate ice crystals $(i)$ by either homogeneous or immersion freezing. Pristine ice crystals grow by deposition of water molecules at their surfaces. The reverse process, sublimation, returns water vapour back to the gas phase. Cooling or heating of air induces water phase transitions conserving total water mass and heat. Water particles and ice crystals compete for the available water vapour. Ice crystals may be removed from the parcel by sedimentation, leading to a loss of total water.

temperatures warmer than $240 \mathrm{~K}$. The model described here has been employed to assess quantitative predictions of our theoretical considerations and to explore the basic features of its underlying concept in greater detail. It includes homogeneous freezing of supercooled aerosol particles below $230 \mathrm{~K}$ and can therefore also be used for future cirrus cloud studies. While we describe how immersion freezing is treated in the framework of the spectral model, detailed studies of IN effects, including the competition between various ice nucleation modes, will be part of future work.

The basic model equations and numerical solution methods presented here are described in section 2. An observation-based case study is analyzed and a number of sensitivity studies are carried out in section 3. A summary of the main findings and their implications for future work in section 4 concludes this article.

\section{Numerical model}

The spectral parcel model primeice has been developed to treat primary ice formation processes - ice nucleation either homogeneously or heterogeneously from aqueous precursor particles and growth by uptake of water vapour - as summarized in Figure 1 and outlined in section 2.1. Its underlying equations and the numerical methods to solve them are described in sections 2.2 and 2.3 , respectively.

\subsection{Salient features}

Supercooled aerosol particles acting as nuclei for water-vapour condensation can turn into nearly pure water (cloud) droplets by overcoming a critical supersaturation with respect to liquid water. Both aerosol and cloud droplets may be regarded as one type of water-containing particles distinguished solely by their water content. The amount of condensed water is controlled by the mass and chemical nature of solute (hygroscopic) material of the CCN and the temporal evolution of supersaturation driven by a dynamical forcing. Aerosol and cloud droplets turn into ice crystals by homogeneous freezing in sufficiently cold and moist conditions. Hygroscopic material dissolved in aqueous particles attracts water molecules, thereby lowering the freezing temperature of pure water. In this way, homogeneous ice nucleation from supercooled solution aerosols can, in the absence of liquid water supersaturation, be suppressed to very low temperatures, e.g. $185-190 \mathrm{~K}$ in the winter polar stratosphere (Peter, 1997), well below the range of temperatures $(\approx 235-239 \mathrm{~K})$ where pure water droplets freeze homogeneously on short timescales (KS16).
As opposed to homogeneous freezing - a stochastic, volumedependent process in fully liquid particles - heterogeneous ice nucleation behaviour is surface-controlled and may vary strongly between individual IN (Murray et al., 2012). In particular, in a given time window, not all IN in a sample might nucleate ice, due to interparticle variability in their ice-nucleating properties. The physico-chemical properties of IN and the temperature and supersaturation at which they form ice vary depending on the ice nucleation mode. In primeIce, besides homogeneous droplet freezing, immersion freezing is represented as a primary heterogeneous ice formation mode. When IN are immersed in water particles (i.e. liquid aerosol particles or cloud droplets and immersion IN are internally mixed; see Figure 1), IN may freeze the host particle around and above homogeneous freezing temperatures.

Another primary ice nucleation mode is deposition nucleation - the nucleation of ice by water-vapour deposition on the bare surfaces of externally mixed particles bypassing a supercooled liquid water stage. It is reasonable to assume that deposition IN have been removed by in-cloud scavenging processes and are no longer present in significant concentrations in cold cloud outflow regions. Moreover, it is fundamentally unclear how to distinguish between immersion and deposition nucleation in parametrizations of heterogeneous ice nucleation rate coefficients in the case of thin aqueous coatings.

Ice particle growth from the vapour phase is modelled using diffusional theory, including a gas kinetic correction, to allow the accurate treatment of aerosol-induced ice formation. This correction introduces the deposition coefficient, defined as the ratio of the number of water molecules incorporated into the ice crystal lattice during growth and the number of water molecules impinging on the ice surface. We use constant values for the deposition coefficient, although in nature it depends on ambient ice supersaturation (Zhang and Harrington, 2013), among other factors. This introduces uncertainty in ice-crystal growth rates, but is unlikely to be critical for simulations of the low-temperature homogeneous freezing process, since the necessary high ice supersaturation results in large values of deposition coefficients.

The removal of ice crystals from the parcel due to sedimentation is implemented in primerce to estimate its potential effect on ice nucleation and growth. This requires assumptions about the vertical depth of the parcel. It seems more appropriate, for that matter, to perform one-dimensional simulations, but such column models require additional assumptions regarding vertical profiles of humidity and temperature. Since nucleation layers are rather shallow (some $10 \mathrm{~m}$ extension: KS16), a fine resolution of those vertical profiles is required. Assumptions about this 
fine-scale structure may at this point be as arbitrary as assigning a fixed layer depth in a parcel model framework, for which reason we opt to work with the latter assumption for first exploration.

The dynamical forcing is in the current version of primeICE represented by a constant, sustained cooling rate (or an equivalent updraught speed). Although it is well recognized that in nature vertical air motions exhibit temporal variability on short timescales, the assumption of constant updraught speeds facilitates both the identification of dynamical ice formation regimes and the interpretation of simulation results.

\subsection{Basic equations}

In primeICE, a large set of coupled, stiff differential equations governing the temporal evolution of heat and particulate water mass during liquid and ice particle growth and ice nucleation (subscript 'nuc') is solved for adiabatic air parcels. Water vapour is transferred towards and away from water particles and ice crystals by condensation/evaporation (con) and deposition/sublimation (dep), respectively. The principle variables describing the water budget are size-dependent particle mass mixing ratios, $q$, and particle number mixing ratios, $\eta$, quantifying the condensed water mass and the particle number per unit mass of air, respectively. Details of the spectral representation of these particle mixing ratios are provided in section 2.3. Both $q$ and $\eta$ are invariant under adiabatic change and are used to build particle size distributions. The evolution of absolute temperature, $T$, embodies variations in the heat budget arising from dynamical (external) forcing and diabatic (internal) processes due to water phase transitions. The forcing also controls the rate of change of air pressure, $p$. Subscripts $v, w, i, c$ indicate water vapour, liquid supercooled water (or water particles), ice water (or ice crystals) and particle core material, respectively (Figure 1). Nonaqueous cores in aerosol particles include soluble matter (sol) and insoluble immersion nuclei (ins). Particle number mixing ratios per unit mass of air are defined by $\eta=n / \rho_{\mathrm{a}}$, with particle number concentrations per unit volume of air $n$ and the mass density of air $\rho_{\mathrm{a}}$. Mass mixing ratios for particulate components with single particle volumes $V$ and bulk mass densities $\rho$ are defined by $q=\rho V \eta$.

Hygroscopic growth of CCNs is simulated in primeICE employing a parametric water activity model based on Köhler theory (Petters and Kreidenweis, 2007). In the $\kappa$-Köhler model, the liquid water-vapour saturation pressure over solution droplets is parametrized using the water activity, $a_{\mathrm{w}}$, in the form

$$
\frac{1}{a_{\mathrm{w}}}=1+\kappa \frac{V_{\mathrm{sol}}}{V_{\mathrm{w}}}, \quad \kappa=\frac{V_{\mathrm{sol}}}{V_{\mathrm{c}}} \kappa_{\mathrm{sol}}+\frac{V_{\mathrm{ins}}}{V_{\mathrm{c}}} \kappa_{\mathrm{ins}},
$$

with the single particle core volume $V_{\mathrm{c}}=V_{\text {sol }}+V_{\text {ins }}$ and where $0 \leq \kappa \leq 1$ is a parameter determined by the chemical nature of the solute and the possible presence of an insoluble particle core $\left(V_{\text {ins }}>0\right)$. Insoluble cores (here, immersion IN) do not contribute to the particle's overall solubility, as by definition $\kappa_{\text {ins }}=0$. This means that the higher the volume fraction of insoluble material in mixed CCN, the higher the ambient supersaturation over liquid water must be for $\mathrm{CCN}$ to activate into cloud droplets. In the case of strongly diluted water particles $\left(V_{\mathrm{w}} \gg V_{\mathrm{c}}\right), a_{\mathrm{w}} \approx 1$.

There are two options in primeIce to generate a cloud droplet size distribution: either the activation of a prescribed dry CCN size distribution into cloud droplets is computed or a cloud droplet size distribution including $\mathrm{CCN}$ cores is prescribed. CCN and immersion IN are treated as particles that are not physically separated (internal mixture); ice crystals resulting from homogeneous and immersion freezing of droplets are represented as a separate particle type. Mass mixing ratios of core material transferred to ice by nucleation are tracked as a function of time. Insoluble cores notably affect water particle properties, e.g. bulk mass densities, only at water subsaturated conditions and ice crystals only during freezing, when the frozen water mass is still small. The average mass density of core material is defined by $\rho_{\mathrm{c}}=\left(V_{\text {sol }} \rho_{\text {sol }}+V_{\text {ins }} \rho_{\text {ins }}\right) / V_{\mathrm{c}}$ in the case of mixed cores.

We adopt conservation laws governing the temporal evolution of all water phases and heat in moist air adiabatic parcels accounting for ice nucleation-induced water phase transitions. Owing to the short ice formation time-scales, radiation-induced temperature changes modify neither the parcel temperature nor the temperature of individual particles significantly; these are therefore set equal.

The evolution of air pressure is given by the hydrostatic equation,

$$
\frac{\mathrm{d} \ln (p)}{\mathrm{d} t}=-\gamma \Gamma_{\mathrm{a}} \frac{w}{T}
$$

where $\gamma=3.5$ is the adiabatic index, $\Gamma_{\mathrm{a}}$ is the dry adiabatic lapse rate and $w>0$ is the assumed updraught speed. Equation (2) allows us to compute the air mass density from the ideal gas law, $\rho_{\mathrm{a}}=p /\left(R_{\mathrm{a}} T\right)$, with the specific gas constant for air, $R_{\mathrm{a}}$.

The transfer of heat between the water phases is embodied in the heat balance equation,

$$
\begin{aligned}
\frac{\mathrm{d} T}{\mathrm{~d} t}= & -\Gamma_{\mathrm{a}} w \\
& +\frac{T}{\epsilon \gamma}[\underbrace{\sum \theta_{\mathrm{w}}\left(\frac{\mathrm{d} q_{\mathrm{w}}}{\mathrm{d} t}\right)_{\text {con }}+\sum \theta_{\mathrm{i}}\left(\frac{\mathrm{d} q_{\mathrm{i}}}{\mathrm{d} t}\right)_{\mathrm{dep}}}_{\text {vapour } \leftrightarrow \text { liquid/solid }} \\
& +\sum \underbrace{\theta_{\mathrm{f}}\left(\frac{\mathrm{d} q_{\mathrm{i}}}{\mathrm{d} t}\right)_{\text {nuc }}}_{\text {liquid } \leftrightarrow \text { solid }}],
\end{aligned}
$$

introducing dimensionless latent heats, $\theta$, normalized by $R_{\mathrm{w}} T$, with the gas constant for water vapour $R_{\mathrm{w}}$ and $\epsilon=R_{\mathrm{a}} / R_{\mathrm{w}}=$ 0.622 . The first term on the right-hand side is the dry adiabatic cooling rate and the other terms account for diabatic heating or cooling due to water phase changes, where $\theta_{\mathrm{f}}=\theta_{\mathrm{i}}-\theta_{\mathrm{w}}$ is the normalized latent heat of fusion. The sums run over all sizes for each particle type. We recall that $q$ and $\eta$ mark spectral particle mixing ratios defining the particle size distributions shown later in this study and do not represent total (size-integrated) values.

Sizes of water particles and ice crystals are derived from the respective total (water and core) single particle volumes $\propto q / \eta$ :

$$
r_{\mathrm{w} / \mathrm{i}}=\left[\frac{3}{4 \pi}\left(V_{\mathrm{w} / \mathrm{i}}+V_{\mathrm{c}}\right)\right]^{1 / 3}
$$

and are interpreted as radii of volume-equivalent spheres.

The rates of change of condensate due to phase transitions are given by

$$
\begin{aligned}
\frac{\mathrm{d} q_{\mathrm{w}}}{\mathrm{d} t} & =\left(\frac{\mathrm{d} q_{\mathrm{w}}}{\mathrm{d} t}\right)_{\text {con }}+\left(\frac{\mathrm{d} q_{\mathrm{w}}}{\mathrm{d} t}\right)_{\text {nuc }}, \\
\frac{\mathrm{d} q_{\mathrm{i}}}{\mathrm{d} t} & =\left(\frac{\mathrm{d} q_{\mathrm{i}}}{\mathrm{d} t}\right)_{\text {dep }}+\left(\frac{\mathrm{d} q_{\mathrm{i}}}{\mathrm{d} t}\right)_{\text {nuc }} .
\end{aligned}
$$

Uptake rates, $\mathcal{Z}$, of water molecules on $\mathrm{CCN}$, cloud droplets and ice crystals of a given size are governed by diffusional growth laws corrected for latent heating/cooling and non-continuum (gas kinetic) effects:

$$
\begin{aligned}
\left(\frac{\mathrm{d} q_{\mathrm{w}}}{\mathrm{d} t}\right)_{\mathrm{con}} & =\mathcal{Z}_{\mathrm{w}}\left(q_{\mathrm{v}}-a_{\mathrm{w}} K_{\mathrm{w}} q_{\mathrm{sat}, \mathrm{w}}\right), \\
\left(\frac{\mathrm{d} q_{\mathrm{i}}}{\mathrm{d} t}\right)_{\mathrm{dep}} & =\mathcal{Z}_{\mathrm{i}}\left(q_{\mathrm{v}}-K_{\mathrm{i}} q_{\mathrm{sat}, \mathrm{i}}\right),
\end{aligned}
$$

with the water-vapour saturation pressures of supercooled water/hexagonal ice $q_{\mathrm{sat}, \mathrm{w} / \mathrm{i}}$ and the Kelvin (curvature) correction $K_{\mathrm{w} / \mathrm{i}}$. For liquid particles, $K_{\mathrm{w}}=\exp \left(A_{\mathrm{w}} / r_{\mathrm{w}}\right)$ with $A_{\mathrm{w}}=1 \mathrm{~nm}$, 
consistent with the $\kappa$-Köhler solubility model. For ice crystals, we use $K_{\mathrm{i}}=\exp \left(A_{\mathrm{i}} / r_{\mathrm{i}}\right)$ with variable $A_{\mathrm{i}}(T)$. The rate of water mass transfer by diffusion from the vapour to particles is defined by

$$
\mathcal{Z}=4 \pi \frac{\beta D}{1+B} n C r, \quad \beta=\frac{1}{1+\lambda / r},
$$

where $D$ is the diffusion coefficient of water molecules in air and $n$ is the number concentration of particles with size $r$. Moreover, $B$ corrects the uptake rate for latent heating; $\beta$ corrects for surface attachment effects becoming important for particles with sizes similar to the mean free path of water molecules in air, to which $\lambda$, containing the deposition coefficient, is proportional; $C$ is the dimensionless capacitance factor [capacitance normalized by volume-equivalent radii from Eq. (4)] accounting for particle shape effects. Equations (6a) and (7) calculate growth of both non-activated aqueous aerosol particles and cloud water droplets.

Ice nucleation in water particles changes the water and ice mass mixing ratios, $q_{\mathrm{w}}$ and $q_{\mathrm{i}}$, according to

$$
\left(\frac{\mathrm{d} q_{\mathrm{i}}}{\mathrm{d} t}\right)_{\text {nuc }}=-\left(\frac{\mathrm{d} q_{\mathrm{w}}}{\mathrm{d} t}\right)_{\text {nuc }}=\left(\mathcal{J}+\mathcal{J}_{\text {ins }}\right) q_{\mathrm{w}}
$$

where $\mathcal{J}$ is the homogeneous freezing rate and $\mathcal{J}_{\text {ins }}$ is the immersion freezing rate. Similar equations hold for the time tendencies of number mixing ratios, $\eta_{\mathrm{i}}$ and $\eta_{\mathrm{w}}$. Moreover, core material in water particles (subscript ' $w, c$ ') is transferred in the same way to ice crystals during droplet freezing. The resulting core mass mixing ratios (subscript 'i,c') follow from

$$
\left(\frac{\mathrm{d} q_{\mathrm{i}, \mathrm{c}}}{\mathrm{d} t}\right)_{\mathrm{nuc}}=-\left(\frac{\mathrm{d} q_{\mathrm{w}, \mathrm{c}}}{\mathrm{d} t}\right)_{\mathrm{nuc}}=\left(\mathcal{J}+\mathcal{J}_{\mathrm{ins}}\right) q_{\mathrm{w}, \mathrm{c}} .
$$

Ice crystals are removed from the parcel by sedimentation according to

$$
\left(\frac{\mathrm{d} y}{\mathrm{~d} t}\right)_{\text {sed }}=-2 \frac{v_{\mathrm{t}}}{\delta z} y, \quad y=\eta_{\mathrm{i}}, q_{\mathrm{i}}, q_{\mathrm{i}, \mathrm{c}}
$$

where $v_{\mathrm{t}}$ is the size-dependent terminal fall speed of ice crystals and $\delta z$ is the prescribed depth of the supersaturated vertical layer the crystals fall into, which is typically larger than the freezing layer depth. The factor 2 accounts for a an assumed homogeneous ice crystal distribution in the layer, which means that the average distance ice crystals must settle before being removed from the parcel is $\delta z / 2$. Ice crystal sedimentation is the only loss process of total water in the parcel depending on the choice of the parcel's vertical dimension. Water particles are too small $(<10 \mu \mathrm{m})$ to settle significantly during homogeneous freezing events. More realistic quantification of sedimentation effects requires the use of at least a one-dimensional model framework with high vertical resolution (Jensen and Pfister, 2004; Lin et al., 2005; Murphy, 2014).

Water vapour saturation pressures and associated latent heats of vaporization are taken from Murphy and Koop (2005). Water mass transfer rates from Eq. (7) are taken from Lamb and Verlinde (2011). We use $\kappa_{\text {sol }}=0.5$ for the CCN hygroscopicity parameter, a value approximately midway between those for marine and continental water-soluble particles (Kreidenweis et al., 2009). This value is reduced tenfold in a sensitivity study modelling rather non-hygroscopic particulate matter. We set $\rho_{\text {sol }}=1.5 \mathrm{~g} \mathrm{~cm}^{-3}$ for simplicity. Homogeneous freezing rates are specified in Appendix A. The deposition coefficient for uptake of water molecules on ice crystals in homogeneous freezing conditions is set equal to 0.7 (Skrotzki et al., 2013); for liquid particles, a value of unity is used. While the small water particles are spherical, a commonly observed shape of pristine ice crystals found in cold $(<250 \mathrm{~K})$ cloud tops is that of hexagonal prisms (plates and columns) (Libbrecht, 2005). Pristine ice crystals in convective cloud tops tend to be isometric (Järvinen et al., 2016), therefore in the current version of primeICE we use capacitance factors and terminal fall speeds for columns with a moderate aspect ratio of 2 (Appendix B). Ice-supersaturated layer depths are varied parametrically corresponding to different ice crystal sedimentation rates.

\subsection{Discretization and numerical solution methods}

To initialize the simulations, a size distribution of dry aerosol particle cores (here without immersion IN) is defined, from which cloud droplets can be activated consistent with the prescribed dynamical forcing. Log-normal size distributions are employed with mean modal radii $r_{\mathrm{m}}$ and geometric standard deviations (spectral widths) $\sigma$. Water may be added to the dry CCN cores to generate an initial cloud droplet size spectrum.

Core particle spectra are discretized according to their sizes, defining NP classes (labels) over a radius range spanning 4 standard deviations away from the modal radius. As water particles, they are allowed to grow and shrink to their exact sizes in a Lagrangian manner. Their growth is therefore numerically non-diffusive, a crucial feature for accurate simulations of droplet freezing.

Ice crystal spectra are discretized into NP grid cells (size bins). In this study, we prescribe $\mathrm{NP}=250$ bins distributed within the radius range $0.01-1000 \mu \mathrm{m}$. Bin volumes within this range increase progressively by a factor of 1.15 . The moving-centre size structure with fixed bin edges and variable bin centres (Jacobson, 1999) is implemented in primerce to treat depositional growth and sublimation of cloud ice. It exhibits very little numerical diffusion. The Lagrangian treatment of water particle growth, along with a fixed size grid for ice crystals, means that we need to locate the ice-crystal bins - corresponding to the actual droplet (water plus core) sizes - into which droplets nucleate.

A number of physical tendencies are integrated as diagnostic variables in order to facilitate the interpretation of results (section 3). Numerical solutions of individual processes are carried out sequentially. A total of $4+6 \mathrm{NP}$ equations for $\left\{p, T, z ; q_{\mathrm{v}}\right\}$ and the distributions $\left\{q_{\mathrm{w}}, \eta_{\mathrm{w}} ; q_{\mathrm{i}}, \eta_{\mathrm{i}} ; q_{\mathrm{w}, \mathrm{c}}, q_{\mathrm{i}, \mathrm{c}}\right\}$ are solved using using a constant time step, $\Delta t$. Fixing the time step requires some experimentation, depending on the model set-up. In most cases, the choice $\Delta t[\mathrm{~s}]=0.1 / w\left(\mathrm{~m} \mathrm{~s}^{-1}\right)$ suffices to simulate homogeneous ice formation processes accurately. For $w=1 \mathrm{~m} \mathrm{~s}^{-1}$, this corresponds to $\Delta t=0.1 \mathrm{~s}$ and a virtual altitude resolution of $10 \mathrm{~cm}$. Accurately resolving homogeneous freezing of rapidly evaporating cloud droplets or hygroscopic growth of non-activated aerosol particles can place even tighter constraints on $\Delta t$.

The distance a parcel travels vertically follows from $\Delta z(t)=w t$. The equations determining the evolution of $p$ and $T$ are integrated explicitly, since time steps appropriate for resolving hygroscopic aerosol growth and ice nucleation are usually small enough to track meteorological or thermodynamic variables accurately. Nucleation and sedimentation equations (affecting $q$ - and $\eta$ condensate and core variables) are integrated fully implicitly. The total water mass balance coupling $q_{\mathrm{v}}$ with $q_{\mathrm{w}}$ and $q_{\mathrm{i}}$ is solved using the Analytical Predictor of Condensation (APC) and Dissolution (APD) schemes (Jacobson, 1999). Those schemes do not require iteration and are exactly mass-conserving, unconditionally stable and highly accurate when using sufficiently small time steps. The APC scheme is applied to solve ice growth, whereas the APD scheme is used to solve water particle growth, since the water saturation vapour pressure over solution droplets - hence the amount of condensable vapour - depends on the amount of dissolved water.

\section{Case studies}

In KS16, we studied systematically how many ice crystals form homogeneously from a given population of cloud droplets across a wide range of updraught speeds, along with associated freezing temperatures. Below, we investigate further details of homogeneous ice formation in the warm cirrus regime with the help of simulations constrained by updraught speed and droplet parameters from aircraft measurements in deep convective cloud tops. We discuss two different simulation set-ups: a baseline case with and without effects of sedimentation using a prescribed cloud droplet spectrum (section 3.1) and cases that capture effects of 
(a)

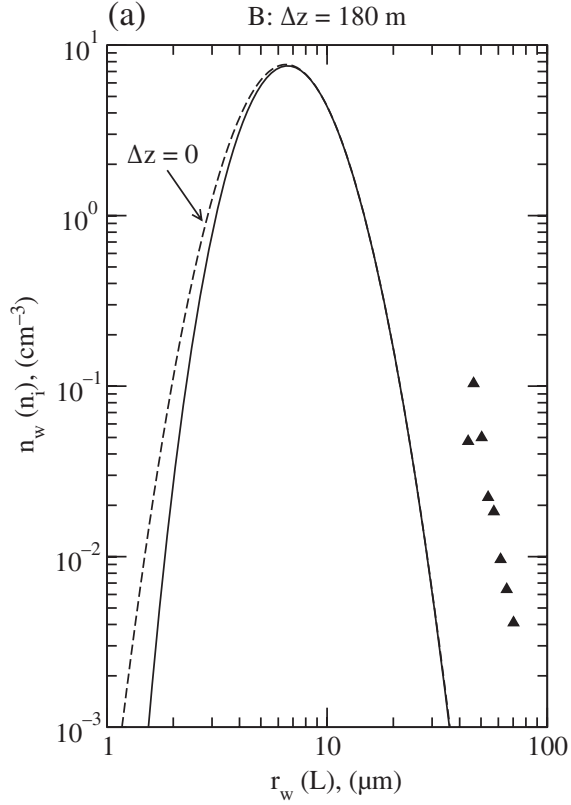

(b)

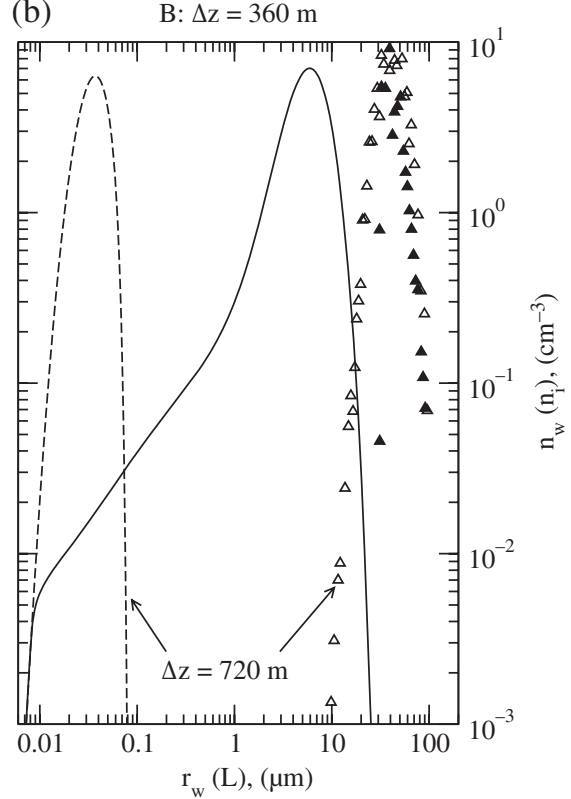

Figure 2. Number concentrations of water particles (curves) and ice crystals (symbols) as a function of total (wet) radius and maximum dimension, respectively, for the deep convective baseline case B. Results (solid curves, filled symbols) are given (a) shortly after homogeneous freezing set in and (b) close to freezing-relaxation. The initial $(\Delta z=0)$ cloud droplet spectrum and the distributions at a late stage well after freezing-relaxation $(\Delta z=720 \mathrm{~m}$, open symbols $)$ are also shown.

cloud droplet formation from activation of CCN prior to or along with homogeneous freezing (section 3.2). Both updraught speed and CCN solubility are varied in separate sensitivity studies.

\subsection{Baseline case}

Guided by the field observations (Rosenfeld and Woodley, 2003), case $\mathrm{B}$ assumes an updraught speed $w=6 \mathrm{~m} \mathrm{~s}^{-1}$ in the deep convective regime and a total water particle number concentration $n_{\mathrm{w}}=500 \mathrm{~cm}^{-3}$. These values are in the range of those reported by a comprehensive cloud model study (Khain et al., 2001). The modal radius and spectral width of the soluble droplet cores, which have not been reported in the measurements, are $r_{\text {sol }}=0.04 \mu \mathrm{m}$ and $\sigma_{\text {sol }}=1.5$, respectively. Liquid water is added to the core particle population such that the modal radius increases to $r_{\mathrm{w}}=6.5 \mu \mathrm{m}$. This yields an initial liquid water content $1.2 \mathrm{~g} \mathrm{~m}^{-3}$ and volume mean radius $8.3 \mu \mathrm{m}$ of the initial cloud droplet population, in the range of and close to the measured values, respectively; they do not increase notably until freezing-relaxation sets in. The time or vertical location of freezing-relaxation is defined as the point where the ice number tendency, $\mathrm{d} n_{\mathrm{i}} / \mathrm{d} t$, due to nucleation - the freezing pulse - reaches its peak (KS16). Simulations start at $240 \mathrm{~K}$ and halt at $234 \mathrm{~K}$ after all ice crystals have formed and depleted the large amount of water vapour available for deposition up to a remaining, smal supersaturation with respect to ice that balances the sustained cooling. The initial air pressure, $388 \mathrm{hPa}$, is inferred from the US standard atmosphere. Ice crystals are not allowed to fall out of the parcel unless otherwise mentioned.

Snapshots of water particle and ice crystal size spectra are shown in Figure 2 at selected distances traveled vertically by the parcel, $\Delta z=0,180,360$ and $720 \mathrm{~m}$, corresponding to parcel ages $t=0,30 \mathrm{~s}, 1 \mathrm{~min}$ and $2 \mathrm{~min}$, respectively.

Comparing the initial droplet spectrum (dashed curve) with that at $\Delta z=180 \mathrm{~m}$ reveals that only the smallest droplets have grown by condensation before the first ice crystals (symbols) form from freezing of the largest droplets. At this level, the air is slightly supersaturated over liquid water, owing to the prescribed cooling that forces droplet growth. Some ice crystals, reaching maximum dimensions $50-70 \mu \mathrm{m}$, have already taken up considerable amounts of water vapour, indicative of large depositional growth rates in the highly ice supersaturated vapour. At $\Delta z=360 \mathrm{~m}(1 \mathrm{~min})$, the three water phases are close to freezing-relaxation (at $388.5 \mathrm{~m}$ ), which means that the number of homogeneously nucleated ice crystals (filled symbols) is at this point high enough to drive the water-vapour concentration below liquid water saturation, forcing the smallest (sub- $\mu \mathrm{m})$ droplets with the highest saturation vapour pressure to evaporate first (solid curve).

At $\Delta z=720 \mathrm{~m}$ (2 min), only a few more ice crystals have formed and the ice crystal population has grown further to a slightly larger mean size (open symbols). More ice crystals are now present at the small size end of the distribution; they have formed on evaporating cloud droplets in the declining supersaturation. At the prevailing temperatures, water particles no longer freeze when their water activity falls below unity. Small cloud droplets that escaped freezing evaporated to their cores and the added water vapour is available for depositional growth of the already frozen droplets (Wegener-Bergeron-Findeisen mechanism). At this altitude, the initially symmetric log-normal core spectrum (not shown) is depleted of the largest particles, which have been activated into the largest droplets that froze preferentially. The air is slightly supersaturated over ice and the remaining supercooled aerosol particles equilibrate almost instantly with the slowly decreasing relative humidity, because they contain only small amounts of liquid water. Diffusional growth becomes very slow for $100 \mu \mathrm{m}$ sized (and larger) ice crystals (Sölch and Kärcher, 2011) and ice-crystal aggregation leads to complex ice-crystal shapes (Schmitt et al., 2016).

The baseline case B and a weak-forcing variant, BwEAK, in which the updraught speed has been reduced by an order of magnitude to $0.6 \mathrm{~m} \mathrm{~s}^{-1}$, are discussed with the help of Figures $3(\mathrm{a})-(\mathrm{h})$, respectively, in terms of the evolution of crucial ice-phase variables. Case BWEAK may be viewed as representative of conditions within outflow regions of extratropical cyclones showing various degrees of convective activity. We show the ice saturation ratio, $S_{\mathrm{i}}=q_{\mathrm{v}} / q_{\mathrm{sat}, \mathrm{i}}$, the total (integrated over all sizes) ice-crystal number concentration, $n_{\mathrm{i}}$, the mean (averaged over the size distribution) maximum ice-crystal dimension, $\langle L\rangle$, and the total ice water content, IWC. Cases without sedimentation (formally obtained by setting the layer depth, $\delta z$, to a very large value) are depicted as solid curves.

We first examine case B (Figure 3). For $\Delta z<250 \mathrm{~m}, S_{\mathrm{i}}$ rises only slightly, resulting from a balance between the cooling of air and the removal of vapour due to droplet condensation. Droplet growth keeps $S_{\mathrm{w}}$ (not shown) close to liquid water saturation. The continuously increasing ice formation rate reaches its peak near $400 \mathrm{~m}$ (filled circle) and ongoing depositional 
(a)

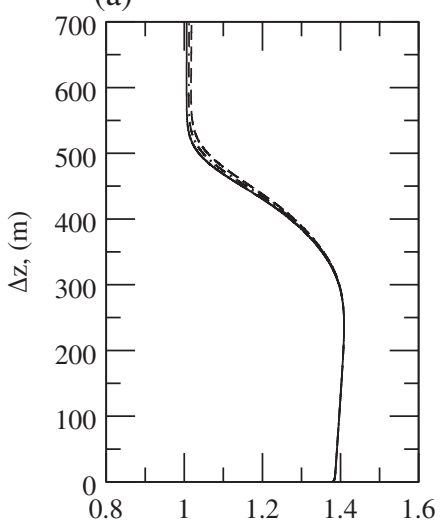

(e)

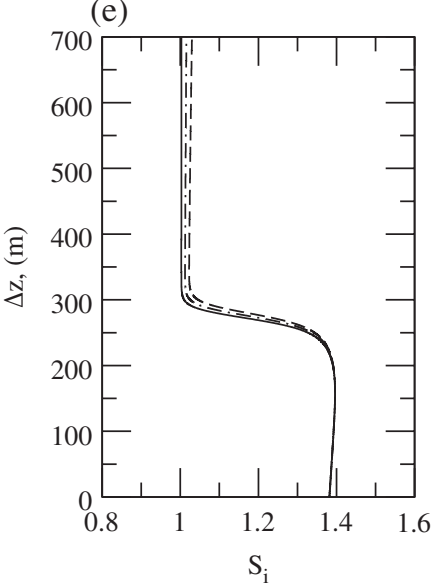

(b)

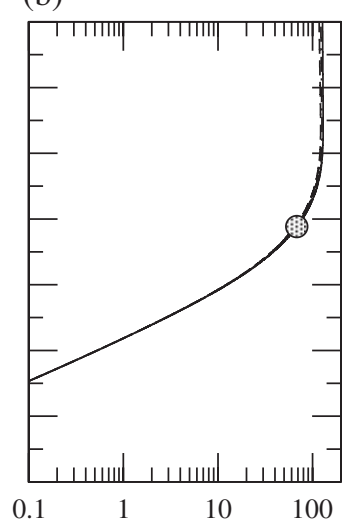

(j)

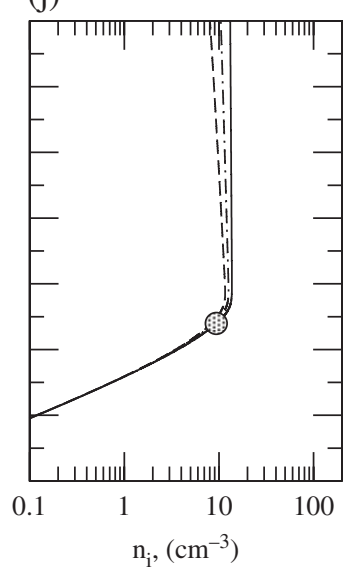

(c)

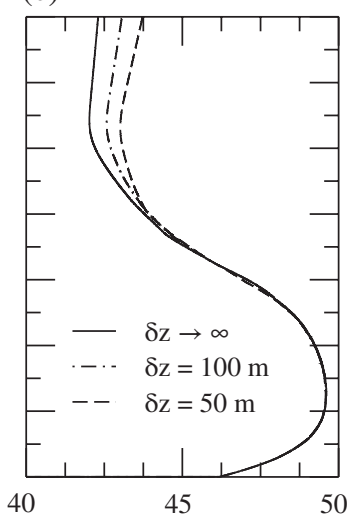

(g)

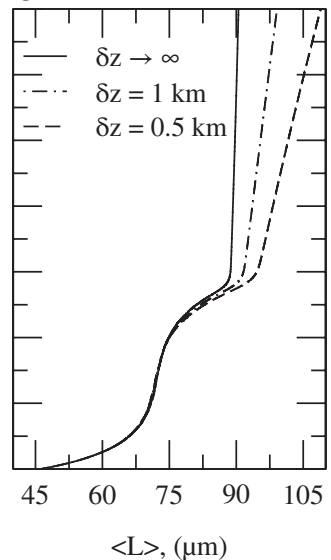

(d)

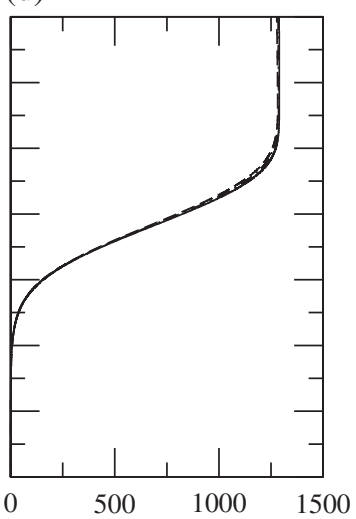

(h)

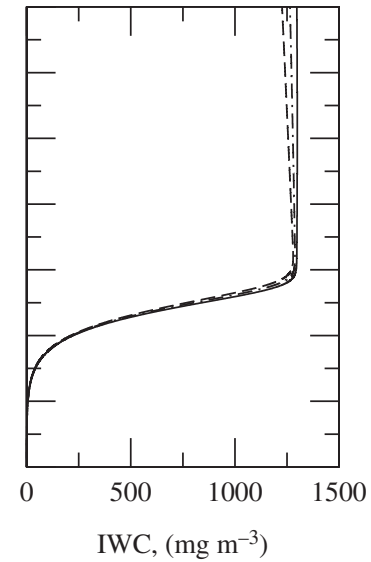

Figure 3. Development of (a,e) ice saturation ratio, $(\mathrm{b}, \mathrm{f})$ total ice-crystal number concentration, $(\mathrm{c}, \mathrm{g})$ mean maximum ice crystal dimension and $(\mathrm{d}, \mathrm{h})$ ice water content for $(\mathrm{a}-\mathrm{d}) w=6 \mathrm{~m} \mathrm{~s}^{-1}$ (case B) and $(\mathrm{e}-\mathrm{h})$ tenfold reduced updraught speed (case BwEAK). Cases without sedimentation $($ solid curves, $\delta z \rightarrow \infty)$ and with parametrized sedimentation using sedimentation layer thicknesses, $\delta z$, as indicated (dashed and dot-dashed curves) are shown. Circles mark the locations of freezing-relaxation, i.e. the freezing pulse maxima; the small differences in the location of circles induced by the different onsets of sedimentation in each case are not shown. Note the change in scale for $\langle L\rangle$ in both panels.

growth leads to a rapid increase in IWC. Soon after the nucleation pulse decays $(\Delta z>500 \mathrm{~m})$, a quasi steady-state is reached with an ice supersaturation $s_{\mathrm{i}}=S_{\mathrm{i}}-1 \approx 0.01$, which slows the increase in IWC dramatically. The mean maximum ice crystal size $<L>$ varies only slightly, initially reflecting the interplay between freezing (favouring the largest droplets) and depositional growth (favouring the smallest crystals). Around freezing-relaxation, $\langle L\rangle$ decreases as the majority of the droplets freeze. Finally, $<L>$ increases again, but only slightly, owing to the very low persistent supersaturation. The quasi steadystate ice supersaturation at higher levels scales $\propto w /\left(n_{\mathrm{i}}<r_{\mathrm{i}}>\right)$ (Korolev and Mazin, 2003).

Generally, the same interpretation holds in case BWEAK. The main difference is seen around freezing-relaxation. Freezing rates remain smaller than depositional growth rates, so that the resulting faster depletion of the vapour causes droplets to evaporate more quickly during freezing than in case B. This contributes to a rapid shutting off of the freezing pulse and a shallow ice nucleation layer (KS16); compare the evolution of $S_{\mathrm{i}}$ and $n_{\mathrm{i}}$. In case $\mathrm{B}, S_{\mathrm{i}}$ decreases less rapidly, since faster cooling leads to lower temperatures and associated higher freezing rates (now faster than the rates at which the growing ice crystals deplete the vapour), leading to continued ice production at higher levels, i.e. a broader freezing pulse. Furthermore, the evolution of $\langle L\rangle$ differs in both cases, consistent with the differences taking place around freezing-relaxation. Mean sizes are larger, due mainly to lower nucleated ice numbers.

Sedimentation losses are included in two additional simulations assuming a range of ice-supersaturated layer depths. Settling of ice crystals begins to affect the evolution of ice variables only at high levels (above the altitude marked by the circles in Figure 3), after the ice crystals have grown to sufficiently large sizes. This implies that ice-crystal settling hardly affects the homogeneous freezing process for updraught speeds around and above $0.6 \mathrm{~cm} \mathrm{~s}^{-1}$, consistent with expectations (KS16). The largest crystals settle most rapidly, decreasing $n_{\mathrm{i}}$ and IWC and increasing the quasi steady-state supersaturation slightly. In case B (BWEAK), this effect sets in below $\delta z=50-100 \mathrm{~m}(0.5-1 \mathrm{~km})$, with $<L>$ responding sensitively to ice crystal removal from the parcel.

\subsection{Effects of CCN activation}

It is not clear how often and how many cloud droplets actually reach cold outflow levels depending on cloud type, aerosol load and meteorological conditions. However, even if water droplets and CCN have been depleted in cloudy parcels arriving in these areas, entrainment of free tropospheric aerosol particles might replenish the $\mathrm{CCN}$ reservoir. Therefore, it is meaningful to carry out further studies (cases BCCN) that differ from case B regarding the initial water particle spectrum. Changes in this spectrum are brought about by lowering the initial relative humidity. Cloud droplets are then generated from liquid water-subsaturated air $\left(S_{\mathrm{w}}<1\right)$ by activation of CCN as the parcel rises and liquid water saturation is surpassed. This alters the moisture and temperature evolution around freezing significantly. The spectral distribution of the soluble cores (solubility parameter $\kappa_{\text {sol }}=0.5$ ) is identical to that from case B. Additionally, one case describing very poor (largely insoluble) $\mathrm{CCN}$ with $\kappa_{\text {sol }}=0.05$ is examined.

Figure 4 shows the development of ice variables in cases BCCN, where cloud droplets first form from activation of CCN at initial liquid water saturation ratios $S_{\mathrm{w}}=0.9$ (dashed curves) and 0.7 (dot-dashed). For comparison, the results for case B from the top panel in Figure 3 (for the same updraught speed $w=6 \mathrm{~m} \mathrm{~s}^{-1}$ ) are repeated (solid curves). In contrast to case $\mathrm{B}$, where condensation 
(a)

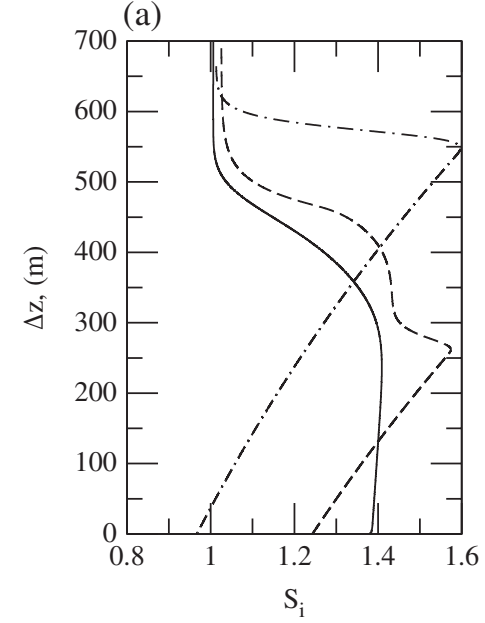

(b)

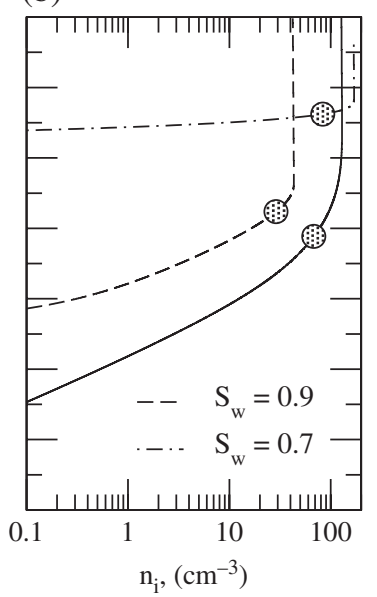

(c)

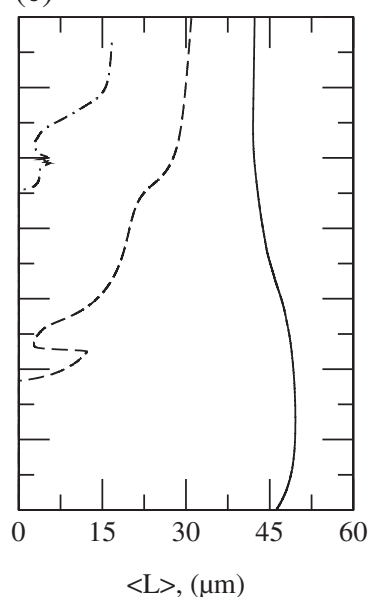

(d)

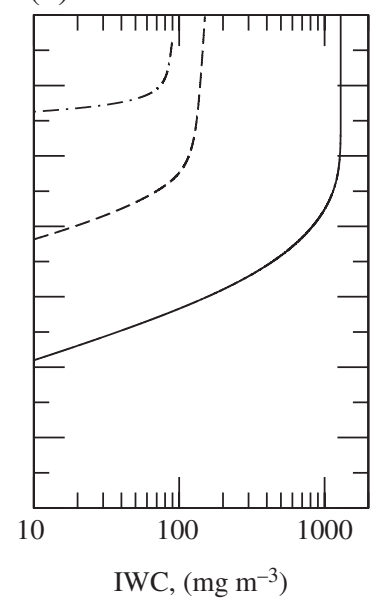

Figure 4. Development of (a) ice saturation ratio, (b) total ice-crystal number concentration, (c) mean maximum ice-crystal dimension and (d) ice water content for the baseline case B with $w=6 \mathrm{~m} \mathrm{~s}^{-1}$ and a preexisting spectrum of cloud droplets (solid curves) and two cases BCCN in which CCN activate into cloud droplets at different initial liquid water saturation ratios (curves with different line styles, initial values $S_{\mathrm{w}}(t=0)$ below liquid saturation, as indicated). Circles mark the locations of freezing-relaxation.

of water vapour on to already existing cloud droplets causes $S_{\mathrm{w}}$ (not shown) to stay approximately constant despite the imposed cooling, the amount of vapour condensing onto the CCN to equilibrate them with the gas phase is very small, leaving the subsaturated gas phase largely unaffected. This causes $S_{\mathrm{i}}$ to rise initially more rapidly in all cases BCCN, due solely to the imposed cooling. After passing through their maxima, $S_{\mathrm{i}}$ values in case BCCN 0.9 decline and level off at water saturation $\left(S_{\mathrm{i}} \approx 1.4\right)$, before declining again at freezing-relaxation and levelling off slightly above ice saturation. Case BCCN 0.7 appears to lack a liquid water saturation stage and freezing-relaxation occurs at a significantly higher (by about $200 \mathrm{~m}$ ) altitude.

According to this discussion, two scenarios might be distinguished. First, in the high $S_{\mathrm{w}}$ case BCCN 0.9, the CCN activation process is terminated (liquid water saturation is reached at $\Delta z=300-400 \mathrm{~m}$ ) before freezing-relaxation sets in (at $\Delta z \approx 400 \mathrm{~m}$ ). This implies that a concept similar to freezing-relaxation, coined activation-relaxation, determines the total number of cloud droplets and describes a situation analogous to the formation of contrails in jet aircraft exhaust plumes (Kärcher et al., 2015). Second, freezing-relaxation occurs before activation-relaxation is completed (low $S_{\mathrm{w}}$ case BCCN 0.7, not showing a liquid water saturation stage), meaning that more water droplets could form for the given cooling rate in the absence of homogeneous freezing. The most crucial factor deciding which scenario is realized for given CCN properties is the updraught speed.

It is instructive to examine the evolution of the parcel temperature. Figure 5 shows the development of $T$ in cases $\mathrm{B}$ and BCCN. In case B, temperature declines initially along the liquid water (moist) adiabate at lapse rate $\mathrm{d} T / \mathrm{d} z \approx-8.7 \mathrm{~K} \mathrm{~km}^{-1}$, due to the presence of the cloud droplets. After homogeneous freezing-relaxation, below $236 \mathrm{~K}$, the lapse rate follows the ice adiabate close to the dry adiabate, $-9.8 \mathrm{~K} \mathrm{~km}^{-1}$.

In the BCCN cases, $T$ decreases initially along the dry adiabate, since the small amount of condensate associated with the hygroscopic growth of the CCN does not significantly affect the heat budget and ice crystals have not yet formed. After cloud droplet formation and still prior to freezing-relaxation, the lapse rate approaches the moist adiabate before making the transition towards the dry adiabate after ice crystal formation; this happens between $\Delta z=250-300 \mathrm{~m}$ in case BCCN 0.9. In this thin layer, the newly formed cloud droplets rapidly quench the relative humidity to water saturation, as discussed by means of Figure 4 .

In case BCCN 0.7, cloud droplets form latest, in range $\Delta z=550-600 \mathrm{~m}$, since longer cooling is required to surpass liquid water saturation owing to the drier initial condition. At the then lower $T(<235 \mathrm{~K})$, homogeneous freezing rates are large

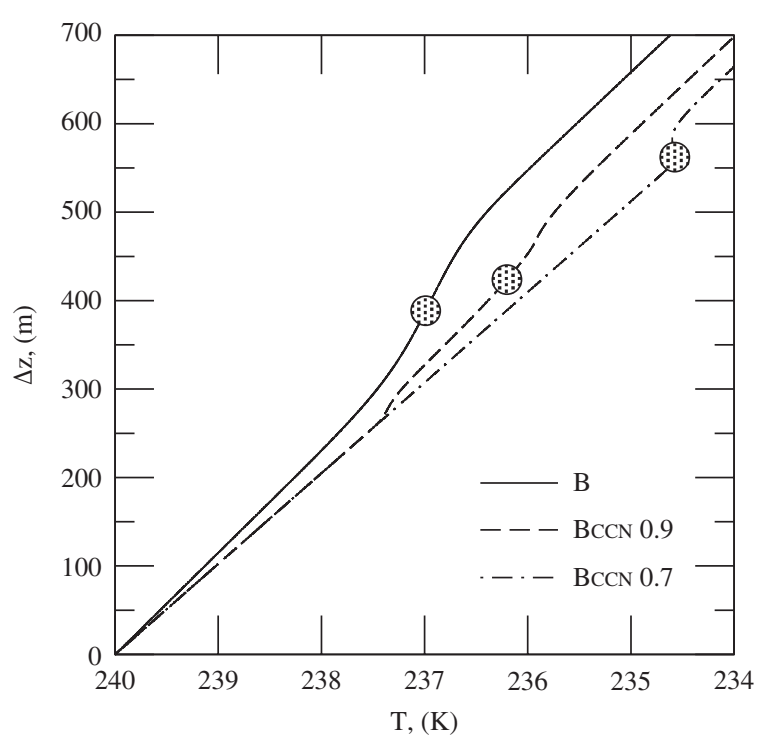

Figure 5. Evolution of temperature for the baseline case $B$ and the two cases BCCN as displayed in Figure $4\left(w=6 \mathrm{~m} \mathrm{~s}^{-1}\right)$. Circles mark the locations where freezing-relaxation takes place, defining the homogeneous freezing temperatures. Lapse-rate changes are caused by the release of latent heat, due mainly to watervapour condensation and deposition.

enough to freeze the droplets virtually instantly; $\mathcal{J}$ increases about 40 -fold upon decreasing $T$ by $1 \mathrm{~K}$ in these conditions (Appendix A). This explains the absence of an extended liquid water saturation stage, cp. $S_{\mathrm{i}}$ in Figure 4.

Homogeneous freezing temperatures (HFTs) - defined as the temperatures where the freezing pulse reaches its peak - vary over more than $2 \mathrm{~K}$, solely by changing the initial relative humidity, i.e. whether or not cloud droplets already exist or are produced by CCN activation. This adds to the marked dependence of the HFTs on updraught speeds (KS16). A few droplets already freeze at temperatures slightly warmer than the HFT, especially in case B where the freezing pulse is broadest, cp. Figure 4; this effect diminishes in the case of CCN activation as $S_{\mathrm{W}}(t=0)$ decreases.

Figure 6 shows water particle and ice crystal size distributions at freezing-relaxation in the two cases BCCN. More than half of the CCN activate into cloud droplets in both cases (fewer in case BCCN 0.7, due to a lower peak supersaturation). The ice crystal size distribution is broader in case BCCN 0.9 , because of the broader freezing pulse (Figure 4). In both cases, the total ice number concentration continues to increase only slightly at levels above freezing-relaxation. In case BCCN 0.9, evaporation is ongoing during freezing, as indicated by the presence of CCN 

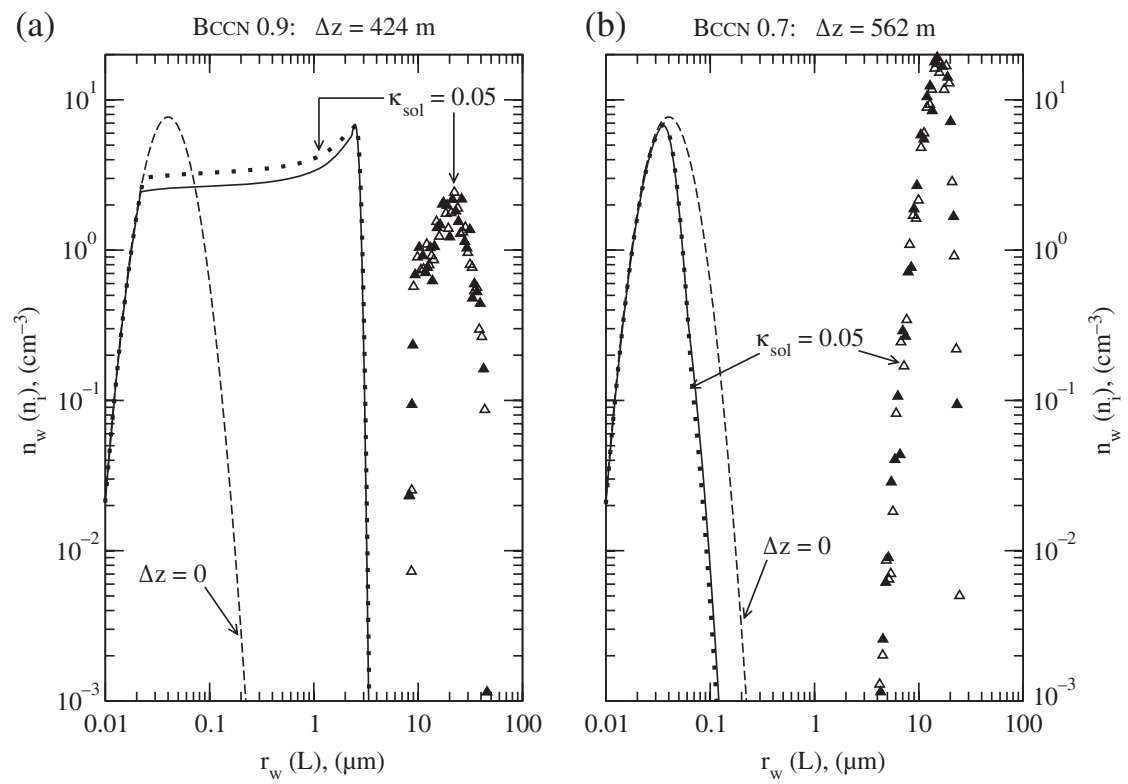

Figure 6. Number concentrations of water particles (curves) and ice crystals (filled symbols) as a function of total (wet) radius and maximum dimension, respectively, for cases (a) BCCN 0.9 and (b) BCCN 0.7. Results are given at freezing-relaxation (corresponding $\Delta z$-values as indicated). Initial CCN spectra are shown as dashed curves $(\Delta z=0)$. For comparison, results obtained for poor CCN $\left(\kappa_{\mathrm{sol}}=0.05\right)$ are also shown at freezing-relaxation (occurring at very similar $\Delta z$ values $)$ as dotted curves (CCN) and open symbols (ice crystals).

residing between their dry and activated sizes; the resulting cloud droplet mode is centred near $3 \mu \mathrm{m}$. In case BCCN 0.7, all unfrozen cloud droplets have already evaporated to their cores at freezing-relaxation.

Revisiting Figure 4, fewer ice crystals form in case BCCN 0.9 relative to $\mathrm{B}$ and $\mathrm{CCN}$ activation leads to a narrower cloud droplet distribution centred at a roughly twofold lower mean radius at freezing-relaxation). As a result, the mean ice crystal size and ice water content are also lower. In case BCCN $0.9, n_{\mathrm{i}}$ is slightly larger than in the baseline case, due to the lower HFT (Figure 5), hence larger freezing rate. This leads to a rather low IWC and a significant further decrease of $\langle L\rangle$.

Changes in ice crystal properties are almost negligible if the cloud droplets are activated from poor CCN (Figure 6). This is due to the high updraught speed $\left(w=6 \mathrm{~m} \mathrm{~s}^{-1}\right)$ and small sensitivity of ice formation on droplet properties in this case (KS16), so that most of the CCN activate almost regardless of the value of $\kappa_{\text {sol }}$. If $w$ were lower, effects of CCN solubility on homogeneous ice formation would be more pronounced.

\section{Discussion and conclusions}

Ice formation in atmospheric clouds is a self-limiting process that bears similarities to the formation of aerosol particles or the activation of CCN into water droplets. In the presence of a dynamical forcing creating an environment in which the parent liquid water phase is metastable, the very creation of the new ice phase terminates its formation by removing the water vapour available for its growth. This sequence of coupled processes is embodied in the theoretical concept of freezing-relaxation. The validity of this concept has been demonstrated by means of numerical simulations of homogeneous freezing events in the warm cirrus regime $(230-240 \mathrm{~K})$. As ice nucleation and growth from the vapour phase are inherently transient and local, the combined effect of cooling, freezing and growth on the number and size of the newly formed ice crystals - for given aerosol and forcing - must be parametrized in most cloud, let alone global, models.

Predictions of freezing-relaxation include the insensitivity of nucleated ice-crystal number concentrations to details of the number and size of freezing droplets and characteristic dependences of ice-crystal number and mean size and homogeneous freezing temperatures on the updraught speed. Moreover, nucleated ice numbers are insensitive to large variations of the homogeneous freezing rate coefficient. In deep convective cloud tops, updraught speeds are large enough to render ice-crystal settling inefficient in depleting the rather shallow freezing layers. At low updraught speeds, droplet evaporation limits droplet freezing.

Little is known about IN in cold cloud outflow regions, except that IN constitute only a very small subset (by number) of CCN and the water droplets evolving from them. Therefore, ice crystals formed on IN presumably grow to much larger sizes and therefore sediment rapidly out of the freezing layer. This further limits their ability to prevent homogeneous freezing from occurring, although IN potentially reduce homogeneously nucleated ice crystal numbers by tapping water vapour and thus slowing the rate of increase in supersaturation at a given updraught speed. In any case, sedimentation quickly dilutes nucleated ice-crystal number concentrations and needs to be taken into account when comparing measured and simulated ice number concentrations.

This study emphasizes the liquid-phase control of anvil ice formation. Water droplets generated at lower cloud levels may not be transported to upper-level outflow regions. They may also form at the threshold to homogeneous freezing from activation of CCN either lofted from lower cloud levels or entrained into convective cells near the cloud tops. Variability in microphysical properties of fresh ice crystals is caused not only by variability in updraught speeds but also by small variations in relative humidity. Both determine how many of the CCN can actually be water-activated and whether the three-phase water system undergoes an extended liquid water stage. The findings presented here indicate that the size spectrum of the CCN is a more important determinant of the activation and subsequent freezing processes than their chemical nature determining particle solubility. Once again, this is due to the strong dynamical control of those processes.

This study investigated homogeneous ice formation in the absence of already existing ice crystals. The basic dependences of homogeneous ice formation on updraught speed and CCN load discussed here are also seen in comprehensive cloud simulations for the same observational case (Khain et al., 2001). However, the absence of lofted ice in detrainment zones as assumed here is unlikely to be a realistic assumption for all deep convective clouds. Ice crystals forming at low levels may reach high-altitude outflow regions by sufficiently strong convective motion overcoming sedimentation. Due to artificial counting errors in airborne particle counters and shattering of ice crystals on the tips of cloud probes (Korolev et al., 2011), there has been considerable debate about the presence of small ice crystals in anvil cirrus. In 
view of the radiative significance of such a small ice-crystal mode, we suggest a systematic exploration of conditions in which lofted ice can suppress homogeneous freezing or CCN activation across a range of deep convective cloud conditions.

These results support ongoing efforts to understand better how cirrus clouds in different dynamical regimes respond to aerosol perturbations (Kärcher, 2017). This includes warm anvil cirrus detrained from convection and low-temperature cirrus forming in situ on supercooled aerosol particles affected by gravity waves and turbulence. Both small-scale gravity waves and localized, intermittent turbulence events are associated with deep convection and create small-scale vertical wind and temperature fluctuations (Podglajen, et al., 2016; personal communication).

We suggest that future process-oriented anvil cirrus simulations should be based on high-resolution trajectories of vertical air motions that resolve convection explicitly. Cloud microphysics should be carried out at least in a one-dimensional (air column) set-up; there is little hope of resolving accurately the sedimentation-induced dilution of freshly nucleated ice crystals and the competition between various ice nucleation modes in Eulerian transport and coarse-bin or bulk microphysical schemes, due to either numerical diffusion or lack of spatial or spectral resolution. A Lagrangian treatment of the ice phase is recommended for this purpose. Finally, studies contrasting stochastic and non-stochastic heterogeneous ice nucleation behaviour, as well as exploring effects of faceted ice-crystal growth and turbulent mixing in future cirrus cloud studies, would also be valuable. However, such efforts might be compromised on the one hand by a striking lack of experimental constraints on heterogeneous ice nucleation rate coefficients and water-vapour deposition coefficients valid for temperatures $<230 \mathrm{~K}$ and on the other hand by insufficient information about frequency of occurrence and properties of turbulence events in the tropopause region.

\section{Acknowledgements}

I am grateful to Graham Feingold for valuable suggestions and a detailed discussion of the first version of this manuscript; to Henrike Wilms for sharing her view regarding the model formulation; to Sue van den Heever for discussing the prospect of better understanding aerosol-ice interactions in convective detrainment zones; and to Jerry Harrington, Eric Jensen and Aurélien Podglajen for stimulating and insightful conversations on the physics and life cycle of cirrus clouds and their dynamical environment.

\section{Appendices}

Appendix A: Homogeneous freezing of liquid aerosol and cloud droplets

Homogeneous freezing rates - the number of ice crystals produced per unit time - follow from $\mathcal{J}=V_{\mathrm{w}} J$, with the water volume $V_{\mathrm{w}}$ (total volume of supercooled water in aqueous particles of a given size) and the rate coefficient, $J$, giving the number of ice germs nucleating per unit time per unit liquid water volume. While the theory of homogeneous freezing has been developed based on several models for $J$ (Khvorostyanov and Curry, 2014, and references therein), in primeIce we employ by default the activity-based parametrization of the rate coefficient, $J\left(T, a_{\mathrm{w}}\right)$, for a seamless treatment of homogeneous aerosol and cloud-droplet freezing (Koop et al., 2000).

In conditions of variable temperature histories, the water activity, $a_{\mathrm{w}}$, is a time-dependent, non-equilibrium quantity calculated using Eq. (1). Homogeneous freezing rate coefficients are extremely sensitive to small variations in $a_{\mathrm{w}}$; water activity and therefore freezing rate coefficients vary significantly across the CCN size spectrum (Haag et al., 2003). Thermodynamic equilibration times for water-vapour uptake on those particles scale $\propto r^{2}$; fine aqueous aerosol particles $(<1 \mu \mathrm{m})$ equilibrate very rapidly with the gas phase (usually within one or a few model time steps); however, their water activity is small - they are more acidic due to the Kelvin effect. This decreases the homogeneous freezing rate coefficients of small aerosol particles dramatically, unless temperatures are very low. In conditions of rapid cooling, $a_{\mathrm{w}}$ might lag behind its equilibrium value in large aerosol particles, due to kinetic limitations for condensation. While this effect is irrelevant in the case of cloud droplets $\left(a_{\mathrm{W}} \simeq 1\right)$, it may be important in the cold cirrus regime $(<230 \mathrm{~K})$ where ice nucleates in much smaller supercooled aqueous aerosol particles in watersubsaturated air $\left(a_{\mathrm{w}}<1\right)$. The importance of the latter effect depends on the magnitude of the cooling rate and on the slope of the large size tail of the particle size distribution. Regardless, in the cases studied here, homogeneous freezing rates are negligible in aerosol particles, since $J$ rises to significant values only in highly ice-supersaturated $\left(S_{\mathrm{i}}>1.5\right)$ and sufficiently cold $(T<$ 230-235 K) air (Jensen and Ackerman, 2006).

The activity-based rate coefficient for pure water droplets may be compared with a parametrization inferred from laboratory measurements that is valid in a narrow temperature range around $235 \mathrm{~K}$ (Riechers et al., 2013). The latter is about 40 times smaller at $T=237 \mathrm{~K}$ than $J\left(T, a_{\mathrm{w}}=1\right)$ and the slope is similar in both cases. The slope is an important parameter, as it determines the characteristic time-scale of homogeneous freezing events (KS16). A more recent parametrization has been developed for homogeneous freezing of pure water that is valid over a larger range of temperatures (Koop and Murray, 2016).

The sensitivity of homogeneously nucleated ice numbers between the different parametrizations is weak, which is a direct consequence of the freezing-relaxation mechanism. For instance, a 40 times lower value of $J$ just means that the air needs to be cooled to a slightly lower temperature (about $1 \mathrm{~K}$ ) to nucleate enough ice crystals quenching the supersaturation and shutting off freezing. At lower temperatures, ice-crystal growth and hence supersaturation quenching is slower and droplet evaporation is also slower. Both tend to increase nucleated ice numbers. As growth and evaporation rates change much less than $\mathcal{J}$, the number of homogeneously nucleated ice crystals increases only slightly. For example, the difference in simulated peak $n_{\mathrm{i}}$ values between both $J$ parametrizations in case B is about $10 \%$, with $n_{\mathrm{i}} \simeq 129 \mathrm{~cm}^{-3}$ when using Koop et al. (2000) and $n_{\mathrm{i}} \simeq 140 \mathrm{~cm}^{-3}$ when applying Riechers et al. (2013). This difference may serve as an indication of the uncertainty in current estimates of homogeneously nucleated ice number concentrations for given liquid water volume and cooling rate in the convective regime.

\section{Appendix B: Ice crystals as hexagonal columns}

The length of a hexagonal column is denoted by $\ell$ and the maximum span across the hexagon by $2 a$, the diameter of a circumscribed circle. The aspect ratio of the column is then defined by $\mathcal{A}=\ell /(2 a)>1$. Setting the volume of a column, $3 \sqrt{3} a^{2} \ell / 2$, equal to $4 \pi r^{3} / 3$, the width of a column, $a$, is related to the radius of a volume-equivalent sphere, $r$, by

$$
a=\left(\frac{9 \sqrt{3}}{4 \pi} \mathcal{A}\right)^{-1 / 3} r
$$

Equation (B1) is used to model ice-crystal shape effects on capacitance (Westbrook et al., 2008):

$$
\mathcal{C}=0.58\left(1+0.95 \mathcal{A}^{3 / 4}\right) a
$$

and on terminal fall speeds, assuming a random falling angle approximation (Westbrook, 2008):

$$
v_{\mathrm{t}}=\frac{g}{6 \pi \eta_{\mathrm{a}}} \frac{m}{\mathcal{C}} .
$$

In Eq. (B3), $g$ is the acceleration due to gravity, $\eta_{\mathrm{a}}$ is the dynamic viscosity of air and $m$ is the single ice-crystal mass. 
The maximum dimension of a column is given by

$$
L=\sqrt{\ell^{2}+(2 a)^{2}}=2 a \sqrt{1+\mathcal{A}^{2}} .
$$

Equation (B4) is used in this study only to display size spectra for non-spherical ice crystal habits. In primeıce, $\mathcal{A}$ is set constant, while in nature $\mathcal{A}$ changes during depositional growth. Small variations of $\mathcal{A}$ do not alter our conclusions.

\section{Appendix C: Notation}

$\begin{array}{ll}\text { Subscripts } & \\ \mathrm{a} & \text { (dry) air } \\ \mathrm{c} & \text { core particle } \\ \mathrm{i} & \text { ice water, ice crystal } \\ \mathrm{v} & \text { water vapour } \\ \mathrm{w} & \text { supercooled liquid water, water } \\ & \text { particle } \\ \text { con } & \text { condensation/evaporation } \\ \text { dep } & \text { deposition/sublimation } \\ \text { ins } & \text { insoluble } \\ \text { nuc } & \text { ice nucleation } \\ \text { sat } & \text { saturation } \\ \text { sol } & \text { soluble } \\ & \end{array}$

HFT homogeneous freezing temperature

IN heterogeneous ice nuclei

IWC ice water content

Units

K

$-$ $\mathrm{kg} \mathrm{m}^{-3}$

Symbols

$a, \ell \quad$ half width (length) of hexagonal column

water activity

$a_{\mathrm{w}}$

$m$

$p$

$q$

$r$

$s$

$\mathrm{s}^{-1}$ single particle mass

air parcel pressure

particle mass mixing ratio

single particle radius

supersaturation

time

ice crystal terminal fall speed

saturation ratio

updraught speed

ice crystal capacitance factor

gas diffusion coefficient

homogeneous freezing rate

coefficient

Kelvin factor

maximum column dimension

air parcel temperature

single particle volume

particle number mixing ratio

bulk particle mass density

ice-supersaturated layer depth

vertical distance travelled by air parcel

lapse rate

dimensionless latent heat of phase

change

column aspect ratio

ice crystal capacitance

ice nucleation rate

water vapour transfer rate to particles solubility parameter

\section{References}

Haag W, Kärcher B, Schaefers S, Stetzer O, Möhler O, Schurath U, Krämer M, Schiller C. 2003. Numerical simulations of homogeneous freezing processes in the aerosol chamber AIDA. Atmos. Chem. Phys. 3: 195-210.

Jacobson MZ. 1999. Fundamentals of Atmospheric Modeling. Cambridge University Press: Cambridge, UK.

Järvinen E, Schnaiter M, Mioche G, Jourdan O, Shcherbakov VN, Costa A, Afchine A, Krämer M, Heidelberg F, Jurkat T, Voigt C, Schlager H, Nichman L, Gallagher M, Hirst E, Schmitt C, Bansemer A, Heymsfield A, Lawson P, Tricoli U, Pfeilsticker K, Vochezer P, Möhler O, Leisner T. 2016. Quasi-spherical ice in convective clouds. J. Atmos. Sci. 73: 3885-3910.

Jensen EJ, Pfister L. 2004. Transport and freeze-drying in the tropical tropopause layer. J. Geophys. Res. 109: D02207. https://doi.org/10.1029/ 2003JD004022.

Jensen EJ, Ackerman AS. 2006. Homogeneous aerosol freezing in the tops of high-altitude tropical cumulonimbus clouds. Geophys. Res. Lett. 33: L08802. https://doi.org/10.1029/2005GL024928.

Kärcher B. 2017. Cirrus clouds and their response to anthropogenic activities. Curr. Clim. Change Rep. 3: 45-57. https://doi.org/10.1007/ s40641-017-0060-3.

Kärcher B, Lohmann U. 2002. A parameterization of cirrus cloud formation: Homogeneous freezing including effects of aerosol size. J. Geophys. Res. 107: 4698. https://doi.org/10.1029/2001JD001429.

Kärcher B, Seifert A. 2016. On homogeneous ice formation in liquid clouds. Q. J. R. Meteorol. Soc. 142: 1320-1334. https://doi.org/10.1002/qj.2735.

Kärcher B, Burkhardt U, Bier A, Bock L, Ford IJ. 2015. The microphysical pathway to contrail formation. J. Geophys. Res. 120: 7893-7927. https://doi. org/10.1002/2015JD023491.

Khain AP, Rosenfeld D, Pokrovsky A. 2001. Simulating convective clouds with sustained supercooled liquid water down to $-37.5^{\circ} \mathrm{C}$ using a spectral microphysics model. Geophys. Res. Lett. 28: 3887-3890. https://doi.org/10. 1029/2000GL012662.

Khvorostyanov VI, Curry JA. 2014. Thermodynamics, Kinetics and Microphysics of Clouds. University Press: Cambridge, NY.

Koop T, Murray BJ. 2016. A physically constrained classical description of the homogeneous nucleation of ice in water. J. Phys. Chem. 145: 211915. https:// doi.org/10.1063/1.4962355.

Koop T, Luo B, Tsias A, Peter T. 2000. Water activity as the determinant for homogeneous ice nucleation in aqueous solutions. Nature 406: 611-614.

Korolev A, Mazin I. 2003. Supersaturation of water vapor in clouds. J. Atmos. Sci. 60: 2957-2974.

Korolev AV, Emery EF, Strapp JW, Cober SG, Isaac GA, Wasey M, Marcotte D. 2011. Small ice particle observations in tropospheric clouds: Fact or artifact? Airborne Icing Instrumentation Evaluation Experiment. Bull. Am. Meteorol. Soc. 92: 967-973. https://doi.org/10.1175/2010BAMS3141.1.

Kreidenweis SM, Petters MD, Chuang PY. 2009. Cloud particle precursors. In Clouds in the Perturbed Climate System, Heintzenberg J, Charlson RJ. (eds.) Strüngmann Forum Report 2: 291-317. The MIT Press: Cambridge, MA.

Lamb D, Verlinde J. 2011. Physics and Chemistry of Clouds. University Press: Cambridge, NY.

Li Z, Xue H, Yang F. 2013. A modeling study of ice formation affected by aerosols. J. Geophys. Res. 118: 11,213-11,227. https://doi.org/10.1002/jgrd. 50861.

Libbrecht KG. 2005. The physics of snow crystals. Rep. Prog. Phys. 68: 855-895.

Lin R-F, Starr DO, Reichardt J, DeMott PJ. 2005. Nucleation in synoptically forced cirrostratus. J. Geophys. Res. 110: D08208. https://doi.org/10.1029/ 2004JD005362.

Murphy DM. 2014. Rare temperature histories and cirrus ice number density in a parcel and a one-dimensional model. Atmos. Chem. Phys. 14: $13013-13022$.

Murphy DM, Koop T. 2005. Review of the vapour pressures of ice and supercooled water for atmospheric applications. Q. J. R. Meteorol. Soc. 131: $1539-1565$.

Murray BJ, O’Sullivan D, Atkinson JD, Webb ME. 2012. Ice nucleation by particles immersed in supercooled cloud droplets. Chem. Soc. Rev. 41: 6519-6554.

Peter T. 1997. Microphysics and heterogeneous chemistry of polar stratospheric clouds. Annu. Rev. Phys. Chem. 48: 785-822.

Petters MD, Kreidenweis SM. 2007. A single parameter representation of hygroscopic growth and cloud condensation nucleus activity. Atmos. Chem. Phys. 7: 1961-1971.

Riechers B, Wittbracht F, Hütten A, Koop T. 2013. The homogeneous ice nucleation rate of water droplets produced in a microfluidic device and the role of temperature uncertainty. Phys. Chem. Chem. Phys. 15: 5873-5887.

Rosenfeld D, Woodley WL. 2003. Deep convective clouds with sustained supercooled liquid water down to $-37.5^{\circ} \mathrm{C}$. Nature 405: 440-442.

m Schmitt CG, Heymsfield AJ, Connolly P, Järvinen E, Schnaiter M. 2016. A

$s^{-1} \quad$ global view of atmospheric ice particle complexity. Geophys. Res. Lett. 43: 
Skrotzki J, Connolly P, Schnaiter M, Saathoff H, Möhler O, Wagner R, Niemand M, Ebert V, Leisner T. 2013. The accommodation coefficient of water molecules on ice - cirrus cloud studies at the AIDA simulation chamber. Atmos. Chem. Phys. 13: 4451-4466.

Sölch I, Kärcher B. 2011. Process-oriented large-eddy simulations of a midlatitude cirrus cloud system based on observations. Q. J. R. Meteorol. Soc. 137: 374-393.

Stith JL, Avallone LM, Bansemer A, Basarab B, Dorsi SW, Fuchs B, Lawson RP Rogers DC, Rutledge S, Toohey DW. 2014. Ice particles in the upper anvil regions of midlatitude continental thunderstorms: The case for frozen drop aggregates. Atmos. Chem. Phys. 14: 1973-1985.

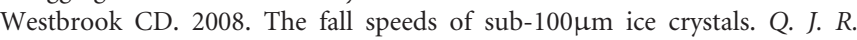
Meteorol. Soc. 134: 1243-1251.

Westbrook CD, Hogan RJ, Illingworth AJ. 2008. The capacitance of pristine ice crystals and aggregate snowflakes. J. Atmos. Sci. 65: 206-219.

Zhang C, Harrington JY. 2013. Including surface kinetic effects in simple models of ice vapor diffusion. J. Atmos. Sci. 71: 372-390. 